Disponível em:

http://editora.unoesc.edu.br/index.php/race

Race, Joaçaba, v. 14, n. 2, p. 623-652, maio/ago. 2015

\title{
HERITAGE ASSETS: PROCEDIMENTOS PARA O RECONHECIMENTO E A MENSURAÇÃO ADO- TADOS PELOS MUSEUS
}

\section{Heritage assets: procedures for the recognition or measurement adopted by museums}

Charline Barbosa Pires

E-mail: charline.pires@gmail.com Mestre em Ciências Contábeis pela Universidade do Vale do Rio dos Sinos; doutoranda em Ciências Contábeis pela Universidade de Brasilia; Professora auxiliar da Universidade do Vale do Rio dos Sinos. Endereço para contato: Avenida Unisinos, 950, Cristo Rei, 93022-000, São Leopoldo, Rio Grande do Sul, Brasil.

\section{Daniel Cerqueira Ribeiro}

E-mail: daniel.dcr09@gmail.com Mestre em Controladoria e Contabilidade pela Universidade de São Paulo; Graduado em Ciências Contábeis pela Universidade de Brasília; Professor do Centro Universitário de Brasília; Perito Criminal Federal do Departamento de Polícia Federal.

Jorge Katsumi Niyama

E-mail: jorgekatsumi@gmail.com

Pós-Doutor pela University of Otago; Doutor em Controladoria e Contabilidade pela Universidade de São Paulo; Professor titular da Universidade de Brasilia.

José Matias-Pereira

E-mail:matias@unb.br

Pós-Doutor em Administração pela Universidade de São Paulo; Doutor em Ciências Políticas pela Universidad Complutense de Madrid; Professor de Administração Pública e Finanças Públicas do Programa de Pós-graduação em Contabilidade da Universidade de Brasília; Pesquisador associado do Programa de Pós-graduação em Contabilidade da Universidade de Brasília.

Artigo recebido em 22 de março de 2015. Aceito em 27 de abril de 2015. 
Resumo

Este artigo teve como objetivo principal efetuar a análise das demonstrações contábeis de museus localizados nos cinco continentes, visando identificar o tratamento contábil relacionado ao reconhecimento e à mensuração dos heritage assets (HAs). Para tanto, aborda as definições de heritage assets, bem como o tratamento contábil discutido na literatura e definido pelas normas aplicáveis aos museus dos países foco deste estudo. Trata-se de uma pesquisa aplicada, qualitativa, descritiva e documental, conduzida a partir da análise do conteúdo dos relatórios anuais, demonstrações contábeis e respectivas notas explicativas de nove museus localizados na Nova Zelândia, Austrália, Reino Unido, África do Sul, Brasil, Canadá, Peru, Argentina e Estados Unidos. A partir da análise dos documentos, verificaram-se práticas heterogêneas, sendo o $H A$ evidenciado em apenas uma parcela dos Balanços Patrimoniais, com destaque para as entidades situadas na Nova Zelândia e na Austrália, as quais apresentam o detalhamento mais completo e robusto. Quanto aos critérios de mensuração adotados pelos museus, o custo histórico é adotado principalmente para o reconhecimento inicial, enquanto outros critérios (valor justo, valor de mercado, custo de reposição e julgamento de profissionais especializados) são utilizados na mensuração subsequente.

Palavras-chave: Museus. Heritage assets. Reconhecimento. Mensuração.

\title{
Heritage assets: procedures for the recognition or measurement adopted by museums
}

\begin{abstract}
This article aimed to make analysis of the financial statements of museums in five continents to identify the accounting treatment for recognition and measurement of heritage assets (HAs). To accomplish this task, BY heritage assets, as well as the accounting treatment discussed in theory and set the standards for museums of the countries wich are the focus of this study. It is an applied, qualitative, descriptive and documentary research conducted by analyzing the content of annual reports, financial statements and related notes of the nine museums, located in New Zealand, Australia, UK, South Africa, Brazil, Canada, Peru, Argentina and the USA. From the analysis of the documents, it was found heterogeneous practices, with the HAs found in only a portion of the balance sheets, especially for institutions located in New Zealand and Australia, which have the most complete and robust detailing. As for the measurement criteria adopted by museums, the historical cost is adopted mainly to initial recognition, while other criteria (fair value, market value, replacement cost and judgment of specialized professionals) are used in the subsequent measurement. Keywords: Museums. Heritage Aassets. Recognition. Measurement.
\end{abstract}

\section{INTRODUÇÃO}

Ao longo dos tempos, a Contabilidade tem sido desafiada a se desenvolver de modo a ser capaz de captar a essência das transações econômicas realizadas 
pelas entidades e, por consequência, de revelar de forma fidedigna a sua posição patrimonial, fornecendo, assim, informações úteis aos seus usuários.

Nessa perspectiva, questões como o reconhecimento e a mensuração dos heritage assets (HAs) mantidos por entidades, como museus, merecem especial atenção, afinal, ainda se faz necessário desenvolver metodologias que reflitam adequadamente os atributos desses ativos culturais, propiciando maior transparência e prestação de contas da gestão desses bens.

A consulta à literatura indica que não há consenso quanto ao tratamento contábil adequado para os $H A$ e que são poucas as publicações de pesquisas aplicadas no que se refere aos critérios de reconhecimentos e mensuração desses elementos. Dessa forma, com o intuito de contribuir com o preenchimento dessa lacuna, este estudo buscou responder à seguinte questão de pesquisa: quais os critérios adotados para o reconhecimento e a mensuração de heritage assets nas demonstrações contábeis de museus?

Com a finalidade de responder à questão formulada, o objetivo central deste artigo foi efetuar a análise das demonstrações contábeis de museus localizados nos cinco continentes, visando identificar o tratamento contábil relacionado ao reconhecimento e à mensuração dos $H A s$. Para a consecução do objetivo definido, abordam-se os critérios sob a perspectiva dos principais autores que tratam do tema, dos normativos emitidos pelos órgãos reguladores dos países pesquisados e da prática adotada pelos museus em suas demonstrações.

A relevância da presente pesquisa para o campo da Contabilidade fica evidenciada quando se percebe que a sistematização e a análise da interação das informações dos critérios de mensuração propostos pela literatura, com os normativos emitidos pelos órgãos reguladores e o tratamento contábil recebido dos heritage assets adotados pelos museus pesquisados, possibilitam uma solidificação e expansão do conhecimento da presente temática. Associado a esse fato, observa-se também que o aprimoramento dos critérios de mensuração e reconhecimento dos heritage assets contribui diretamente para a transparência da gestão e da prestação de contas (accountability) desses ativos.

\section{REFERENCIAL TEÓRICO}

Considerando os objetivos definidos para esta pesquisa, nesta seção apresentamse as definições de heritage assets, bem como o tratamento contábil discutido na literatura e definido pelas normas aplicáveis aos museus dos países foco deste estudo. 


\section{1 DEFINIÇÕES DE HERITAGE ASSETS}

De acordo com Ellwood e Greenwood (2014), uma das primeiras definições acerca dos heritage assets foi proposta por Mautz (1981), que, inicialmente, sugeriu a classificação desses bens como passivos, uma vez que consumem fluxos de caixa ao invés de gerá-los. Já em um segundo momento, evoluindo na discussão do tema, o autor apresentou a definição de facilidades, ou facilities, definido esses bens como aqueles necessários para que as entidades, sem finalidade lucrativa, sejam capazes de exercer suas atividades, e que são adquiridos para facilitar a transferência de recursos aos membros externos a elas (MAUTZ, 1988).

Pallot (1990), por sua vez, utiliza outro termo: ativos comunitários (community assets). Para a autora, esse tipo de ativo diferencia-se dos demais porque os direitos de propriedade são da comunidade, e não do Governo ou de indivíduos.

Barton (2000, p. 220) apresenta o conceito de public heritage facilities (PHF), que "[...] compreende ativos físicos que uma comunidade pretende preservar indefinidamente devido à sua importância cultural, histórica, recreativa ou ambiental." O autor explica que esses ativos pertencem à nação, e o Governo, como seu fiel depositário, é responsável por administrá-los em benefício da sociedade.

Entre as características importantes e que dizem respeito aos bens definidos como public heritage facilities quando se consideram os propósitos contábeis, Barton (2000) cita as seguintes:

a) não visam ganhos financeiros e não são utilizados nas atividades do Governo;

b) as fontes de financiamento são os tributos e/ou doações; cobranças de usuários, quando são realizadas, contribuem com uma pequena parte do valor necessário para a manutenção desses bens;

c) em razão de seus atributos especiais, são mantidos em boas condições perpetuamente, para que as gerações presentes e futuras possam usufruir deles;

d) não estão disponíveis para a venda;

e) os benefícios fluem para os seus usuários (público), e não para a entidade gestora; 
f) o público é encorajado a ser usuário por meio de materiais promocionais e do acesso livre ou de entradas a valores baixos.

Adicionalmente, esses ativos diferenciam-se dos bens privados porque possuem consumo não rival e não excludente. Barton (2005), ao definir os public heritage assets, explica que o consumo não rival está relacionado ao fato de que o consumo desses bens (visitas a museus e galerias de artes) não reduz o volume de serviços disponíveis para os outros usuários potenciais. Ao mesmo tempo, são não excludentes porque todos os cidadãos possuem direitos iguais de acesso aos benefícios gerados por um bem e nenhum cidadão tem a capacidade de impedir o acesso de outro, uma vez que não tem o direito de propriedade sobre o ativo (BARTON, 2005).

No âmbito das normas internacionais, a definição de heritage assets está prevista no IPSAS 17 - Property, Plant and Equipment, emitido pelo International Public Sector Accounting Standard (IPSAS). O IPSAS 17 define, em seu item 9, que alguns ativos são classificados como heritage assets em razão da sua significância cultural, ambiental e histórica. Tais ativos possuem as seguintes características:

a) o seu valor em termos culturais, ambientais, educacionais e históricos provavelmente não é refletido, de forma plena, em valores financeiros baseados apenas em preços de mercado;

b) em razão de proibições ou restrições impostas por obrigações legais ou estatutárias, esses ativos não estão disponíveis para a venda;

c) normalmente, esses ativos são insubstituíveis e estão sujeitos à valorização, apesar da deterioração das suas condições físicas;

d) pode ser difícil estimar a vida útil desses ativos, que, em alguns casos, pode ser de centenas de anos.

Observa-se que são diversas as definições de heritage assets propostas, e a partir delas é possível identificar as características que são inerentes a esses ativos e que podem dificultar o processo de mensuração e reconhecimento.

Uma vez discutidos os aspectos conceituais relacionados aos $H A s$, realiza-se, a seguir, uma revisão da literatura e das normas que abordam o tratamento contábil desses elementos. 


\section{2 RECONHECIMENTO E MENSURAÇÃO DOS HERITAGE ASSETS}

Para Hooper, Kearins e Green (2005), mais complexa do que a contabilização dos ativos de um modo geral é a contabilização dos heritage assets, pois esses bens estão sujeitos a diferentes tratamentos, definidos pelos diversos órgãos reguladores e, além disso, não existe consenso, na literatura, sobre qual seria o tratamento mais adequado.

Micallef e Peirson (1997), por exemplo, defendem que a mensuração dos heritage assets é possível e que a representação fiel da situação de uma entidade requer que esses ativos sejam mensurados e incluídos nas demonstrações contábeis. Em contraponto, Carnegie e Wolnizer (1995) argumentam que coleções de itens culturais, hereditários e científicos não podem ser mensuradas em termos financeiros, bem como não satisfazem aos critérios para serem reconhecidos como ativos. "[...] recursos que não geram fluxos de caixa futuros, direta ou indiretamente, dentro do contexto organizacional existente não deveriam ser reconhecidos como ativos no conjunto de demonstrações contábeis auditadas.” (CARNEGIE; WOLNIZER, 1995, p. 88).

Biondi e Lapsley (2014), por sua vez, indicam que as dificuldades envolvidas no processo de reconhecimento e mensuração dos heritage assets podem limitar o potencial da contabilidade de gerar informações que sejam úteis para os usuários. Para os autores, se a mensuração dos ativos não for realizada a partir de bases consistentes, as informações disponibilizadas podem atrapalhar a compreensão da situação financeira da entidade.

Assim, de maneira geral, pode-se afirmar que a principal questão relacionada ao reconhecimento dos heritage assets diz respeito à sua mensuração, ou melhor, à dificuldade de fazê-lo de forma satisfatória. Ainda que seja possível afirmar que esse tipo de ativo possui um "valor", medido em termos culturais, nem sempre é possível mensurar, em termos monetários, esse atributo (WILD, 2013).

Ao mesmo tempo que a literatura prevê uma série de critérios que poderiam ser empregados na mensuração dos heritage assets, ela destaca, também, as limitações de cada um deles, conforme se observa a seguir. 
Quadro 1 - Critérios de mensuração propostos pela literatura

\begin{tabular}{|c|c|c|}
\hline \multicolumn{2}{|c|}{ Critério de mensuração } & Principais limitações \\
\hline $\begin{array}{l}\text { Avaliação Contin- } \\
\text { gente } \\
\text { Porter (2004) e } \\
\text { Manetti e Va- } \\
\text { leri (2012 apud } \\
\text { LANDRIANI; } \\
\text { POZZOLI, 2014) }\end{array}$ & $\begin{array}{l}\text { Abordagem simulada; } \\
\text { Avalia quanto as pessoas } \\
\text { estariam dispostas a pagar para } \\
\text { obter o benefício ou aceitar } \\
\text { como compensação por serem } \\
\text { privadas desse benefício; } \\
\text { Objetiva mensurar os benefícios } \\
\text { do uso (ou não uso) dos HAs. }\end{array}$ & $\begin{array}{l}\text { Possibilidade de viés nas res- } \\
\text { postas. }\end{array}$ \\
\hline $\begin{array}{l}\text { Custo de reposição } \\
\text { Barton (2005) }\end{array}$ & $\begin{array}{l}\text { Definido com base no valor de } \\
\text { substituição dos } H A s \text {. }\end{array}$ & $\begin{array}{l}\text { Dadas as suas características pe- } \\
\text { culiares, os } H A s \text { não podem ser } \\
\text { substituídos sem que percam o } \\
\text { valor original. }\end{array}$ \\
\hline $\begin{array}{l}\text { Custo de viagem } \\
\text { Porter (2004) }\end{array}$ & $\begin{array}{l}\text { Considera o custo de viagem, } \\
\text { que é uma proxy para a taxa de } \\
\text { entrada (visitantes). Considera, } \\
\text { portanto, a disposição dos usu- } \\
\text { ários em pagar para ter acesso } \\
\text { aos HAs. }\end{array}$ & $\begin{array}{l}\text { Não mensura os benefícios do } \\
\text { não uso. }\end{array}$ \\
\hline $\begin{array}{l}\text { Custo histórico } \\
\text { Carnegie e } \\
\text { Wolnizer (1995), } \\
\text { Barton (2005), } \\
\text { Micallef e Peirson } \\
\text { (1997) e Porter } \\
\text { (2004) }\end{array}$ & $\begin{array}{l}\text { Definido a partir dos preços de } \\
\text { aquisição dos itens comprados. }\end{array}$ & $\begin{array}{l}\text { Não possuem relevância quan- } \\
\text { do as aquisições são realizadas } \\
\text { em momentos distantes; } \\
\text { Custos históricos de coleções } \\
\text { são de difícil definição; } \\
\text { Nem sempre um custo está } \\
\text { associado à compra de determi- } \\
\text { nado ativo; } \\
\text { A vida útil desses bens é longa ou } \\
\text { indefinida, logo, o custo histórico } \\
\text { não é capaz de refletir os benefí- } \\
\text { cios desse ativo. }\end{array}$ \\
\hline $\begin{array}{l}\text { Fair value } \\
\text { Barton (2005) }\end{array}$ & $\begin{array}{l}\text { Valor que seria recebido pela } \\
\text { venda dos } H A s \text { em uma transa- } \\
\text { ção não forçada entre partici- } \\
\text { pantes do mercado. }\end{array}$ & $\begin{array}{l}\text { Inexiste mercado ativo em razão } \\
\text { da natureza social dos benefícios } \\
\text { e restrições à venda; } \\
\text { O preço de mercado, ainda que } \\
\text { identificável, não tem condições } \\
\text { de refletir os benefícios sociais } \\
\text { do bem, dada a sua transferência } \\
\text { para um comprador particular. }\end{array}$ \\
\hline $\begin{array}{l}\text { Julgamento de } \\
\text { profissionais especia- } \\
\text { lizados } \\
\text { Landriani e } \\
\text { Pozzoli (2014); } \\
\text { Carnegie e Wol- } \\
\text { nizer (1995) }\end{array}$ & $\begin{array}{l}\text { Avaliações realizadas por es- } \\
\text { pecialistas, como curadores de } \\
\text { museus; } \\
\text { Preferencialmente, a mensu- } \\
\text { ração deve ser feita a partir da } \\
\text { busca de consenso entre diver- } \\
\text { sos profissionais. }\end{array}$ & $\begin{array}{l}\text { As preferências pessoais do } \\
\text { avaliador podem influenciar na } \\
\text { definição dos valores. }\end{array}$ \\
\hline
\end{tabular}




\begin{tabular}{|c|c|c|}
\hline $\begin{array}{l}\text { Valor de perda } \\
\text { Porter (2004) }\end{array}$ & $\begin{array}{l}\text { Perda total que o proprietário } \\
\text { pode esperar sofrer se for priva- } \\
\text { do de sua propriedade. }\end{array}$ & $\begin{array}{l}\text { Requer o uso da menor quantia } \\
\text { entre o custo de reposição (custo } \\
\text { de comprar ou produzir o ativo) e } \\
\text { o valor recuperável (maior quan- } \\
\text { tia entre o valor realizável líquido } \\
\text { e o valor presente líquido); } \\
\text { O custo de reposição é de difícil } \\
\text { mensuração, e é improvável que } \\
\text { um valor recuperável positivo } \\
\text { possa ser apurado; logo, o valor } \\
\text { a ser atribuído seria zero. }\end{array}$ \\
\hline $\begin{array}{l}\text { Valor de troca } \\
\text { Carnegie e Wol- } \\
\text { nizer (1995) }\end{array}$ & $\begin{array}{l}\text { É a quantia de dinheiro pela } \\
\text { qual o } H A \text { poderia ser trocado } \\
\text { no mercado; } \\
\text { O valor de mercado é objetivo e } \\
\text { pode ser verificado por qualquer } \\
\text { pessoa interessada e com conhe- } \\
\text { cimento de mercado. }\end{array}$ & $\begin{array}{l}\text { É discutível, na medida em que } \\
\text { os bens não estão livres para } \\
\text { serem transacionados pelas } \\
\text { entidades mantenedoras. }\end{array}$ \\
\hline $\begin{array}{l}\text { Valor em uso } \\
\text { Carnegie e Wol- } \\
\text { nizer (1995) }\end{array}$ & $\begin{array}{l}\text { Representa o valor de um item } \\
\text { para o seu dono. É específico } \\
\text { para cada usuário e uso; } \\
\text { Determinado pelo fluxo de caixa } \\
\text { líquido que se espera receber do } \\
\text { seu uso. Baseado no conheci- } \\
\text { mento do preço de compra e das } \\
\text { características físicas (ou legais) } \\
\text { do ativo e em uma expectativa do } \\
\text { seu ganho ou poder de receita- } \\
\text {-produção. }\end{array}$ & $\begin{array}{l}\text { Irrelevante quando o dono } \\
\text { do bem não é o usuário - os } \\
\text { benefícios derivados do uso não } \\
\text { fluem para o mantenedor, mas } \\
\text { para a sociedade como um todo. }\end{array}$ \\
\hline $\begin{array}{l}\text { Valor nacional } \\
\text { Landriani e Po- } \\
\text { zzoli (2014) }\end{array}$ & $\begin{array}{l}\text { Surge da ideia de que, para os } \\
\text { propósitos da administração, } \\
\text { "[...] é referível que o balanço } \\
\text { apresente um valor por mais } \\
\text { questionável que seja do que } \\
\text { nenhum valor." (LANDRIANI; } \\
\text { POZZOLI, 2014, p. 2759). }\end{array}$ & $\begin{array}{l}\text { As informações disponíveis } \\
\text { podem ser questionáveis. }\end{array}$ \\
\hline $\begin{array}{l}\text { Valor presente } \\
\text { líquido } \\
\text { Gibson (1996 } \\
\text { apud PORTER, } \\
2004)\end{array}$ & $\begin{array}{l}\text { Definido com base nos fluxos } \\
\text { de caixa futuros a serem gerados } \\
\text { pelos } H A s \text {, trazidos a valor } \\
\text { presente com o uso de uma taxa } \\
\text { de desconto. }\end{array}$ & $\begin{array}{l}\text { A taxa de desconto é de difícil } \\
\text { definição, considerando a longa } \\
\text { vida útil do ativo e os fluxos de } \\
\text { caixa futuros incertos. }\end{array}$ \\
\hline $\begin{array}{l}\text { Valor realizável } \\
\text { líquido } \\
\text { Porter (2004) }\end{array}$ & $\begin{array}{l}\text { Valor líquido que se espera rece- } \\
\text { ber a partir da venda dos } H A s \text {. }\end{array}$ & $\begin{array}{l}\text { Mercados ativos são raros para } \\
\text { esse tipo de bem e ativos simi- } \\
\text { lares não podem ser utilizados } \\
\text { em razão das características } \\
\text { singulares dos heritage assets. }\end{array}$ \\
\hline
\end{tabular}




\begin{tabular}{|l|l|l|}
\hline Valor recuperável & $\begin{array}{l}\text { Quantia recuperável repre- } \\
\text { sentada pelos fluxos de caixa } \\
\text { decorrentes do uso contínuo e } \\
\text { subsequente alienação dos } H A s .\end{array}$ & $\begin{array}{l}\text { Não pode ser definido na medi- } \\
\text { da em que inexiste um fluxo de } \\
\text { caixa e de vendas. }\end{array}$ \\
\hline
\end{tabular}

Fonte: adaptado de Pires e Niyama (2014).

\section{3 ESTUDOS ANTERIORES}

Da revisão bibliográfica realizada para a presente pesquisa, observa-se uma carência de trabalhos e estudos científicos que adotam os critérios de mensuração propostos pela literatura (sintetizados no Quadro 1) com a finalidade de analisar e discutir de forma empírica aqueles que seriam os mais adequados para a mensuração dos heritage assets. Nessa perspectiva, cabe relatar que foi identificada a pesquisa relacionada aos HAs de museus, realizada na Espanha e de autoria de Plaza (2010), a qual foi intitulada Valuing museums as economic engines: Willingness to pay or disconting of cash-flows? e evidenciou que a valoração econômica por meio de uma estimativa do modelo de viagem (disposição de pagar) é insuficiente e apontou que o método de fluxo de caixa descontado seguido da disposição de pagar é um modelo mais acurado.

Bedate, Herrero e Sanz (2004), por sua vez, adotaram o método do custo de viagem para estimar a curva de demanda e calcular o valor excedente do consumidor para bens culturais (evento artístico cultural; aldeia que compreende um conjunto histórico e catedral) na região da Castilha y Leon na Espanha. Ao final do estudo, os autores concluem que o número de turistas pode ser considerado um indicador de intensidade das preferências individuais, que independe do valor cultural dos locais estudados, sendo essa uma das críticas ao método adotado. Por outro lado, afirmam que o método é capaz de fornecer, pelo menos, uma medida das preferências individuais e sociais no que diz respeito ao patrimônio histórico, visto que o significado da informação dependerá das premissas adotadas no modelo e da forma como seus resultados serão utilizados.

No âmbito nacional, foi identificada a pesquisa de Marques (2012), a qual teve por objetivo analisar as diferenças e implicações para a Contabilidade quando da aplicação das variações individual, zonal e híbrida do método do custo da viagem nos ativos culturais de Brasília (Catedral, Torre de TV e Praça dos Três Poderes). O resultado do estudo mostrou que as mensurações apresentaram grandes variações de acordo com a abordagem utilizada, sendo a abordagem individual a mais adequada, por ter encontrado maior quantidade de sinais de coeficientes correspondentes às 
expectativas, bem como de relações de significância. Marques (2012) ressalta que, em decorrência das variações nas mensurações realizadas, uma possível implicação para a Contabilidade é o não reconhecimento desses ativos nas demonstrações financeiras.

Lopes e Freire (2014) também utilizaram o método do custo de viagem em sua pesquisa, com a finalidade de mensurar o valor dos ativos ambientais de Cavalcante, GO. Foi evidenciado que o valor de $\mathrm{R} \$ 4.873,76$ representa o montante que o turista se predispõe a pagar para ter acesso aos HAs ambientais do citado Município. Outro achado foi a constatação de que os gestores municipais têm a percepção de que as informações geradas pelo método do custo de viagem são relevantes no contexto da tomada de decisão no desenvolvimento de políticas públicas locais.

Considerando a escassez de discussões empíricas dos modelos propostos pela literatura, verifica-se uma oportunidade para que pesquisadores discutam os critérios de mensuração mais adequados para os $H A s$, analisando a realidade de diversas áreas e dos vários critérios de mensuração, com a finalidade de se compararem os resultados gerados pelos métodos utilizados, aprimorando a qualidade informacional dos relatórios contábeis.

\section{4 NORMAS PARA O RECONHECIMENTO E A MENSURAÇÃO DOS HERITAGE ASSETS}

Observa-se que nas últimas duas décadas a contabilidade tem sido demandada por seus usuários em diversas partes do mundo a fornecer o adequado tratamento aos heritage assets nas demonstrações contábeis das entidades que os mantêm, principalmente no que se refere ao reconhecimento e à mensuração.

Diante dessa perspectiva, os órgãos normatizadores vinculados a cada país enfrentam dificuldades na elaboração de normativos, considerando as características intrínsecas desses ativos, conforme debatido anteriormente.

A análise apresentada nesta seção tem como escopo o que definem as normas aplicáveis aos nove países que fazem parte deste estudo (Nova Zelândia, Austrália, Reino Unido, África do Sul, Peru, Canadá, Brasil, Argentina e Estados Unidos) e à International Federation of Accountants (IFAC) em relação ao reconhecimento e à mensuração dos heritage assets nas demonstrações contábeis e respectivas Notas Explicativas (NEs). As principais diretrizes dos respectivos órgãos reguladores estão sumarizadas no Quadro 2, apresentado a seguir. 
Quadro 2 - Tratamento contábil dos heritage assets (HAs) segundo órgãos reguladores

\begin{tabular}{|c|c|}
\hline \multicolumn{2}{|c|}{$\begin{array}{l}\text { Nova Zelândia } \\
\text { Financial Reporting Standard } 3 \text { - Accounting for Property, Plant And Equipment }\end{array}$} \\
\hline Capitalização & $\begin{array}{l}\text { Os } H A s \text { são contabilizados no ativo, sendo mensurados } \\
\text { pelo custo. }\end{array}$ \\
\hline Mensuração subsequente & A reavaliação pode ter como base o custo ou o fair value. \\
\hline $\begin{array}{l}\text { Doações ou aquisição por } \\
\text { valores simbólicos }\end{array}$ & O ativo deverá ser avaliado a fair value. \\
\hline Apresentação & A contabilização é realizada com outros ativos tangíveis. \\
\hline Observação & $\begin{array}{l}\text { Requer um alto nível de detalhamento em NEs. A norma } \\
\text { contábil está em processo de transição, sendo desenvolvida } \\
\text { com base nos IPSAS atuais, tendo a previsão de adoção } \\
\text { integral para os relatórios } 2014 / 2015 \text {. }\end{array}$ \\
\hline \multicolumn{2}{|c|}{$\begin{array}{l}\text { Austrália } \\
\text { Australian Accounting Standard AASB } 116 \text { - Property, Plant and Equipment }\end{array}$} \\
\hline Capitalização & $\begin{array}{l}\text { Os } H A s \text { são contabilizados no ativo, sendo mensurados } \\
\text { pelo custo. }\end{array}$ \\
\hline Mensuração subsequente & $\begin{array}{l}\text { A reavaliação pode ter como base o custo ou o fair value. } \\
\text { Pode ser adotado o teste de impairment, e considerando que } \\
\text { alguns } H A s \text { não possuem vida útil definida, admite-se a } \\
\text { não adoção de depreciação. }\end{array}$ \\
\hline $\begin{array}{l}\text { Doações ou aquisição por } \\
\text { valores simbólicos }\end{array}$ & O ativo deverá ser avaliado a fair value. \\
\hline Apresentação & A contabilização é realizada com outros ativos tangíveis. \\
\hline Observação & Requer um alto nível de detalhamento em NEs. \\
\hline \multicolumn{2}{|c|}{$\begin{array}{l}\text { Reino Unido } \\
\text { Financial Reporting Standard } 30 \text { - heritage assets }\end{array}$} \\
\hline Capitalização & $\begin{array}{l}\text { Quando o custo for maior que o benefício da informação } \\
\text { produzida pelo reconhecimento dos } H A s \text {, não há necessi- } \\
\text { dade de ativá-lo, mas é preciso evidenciar em NEs. }\end{array}$ \\
\hline Mensuração subsequente & $\begin{array}{l}\text { Os HA podem ser avaliados por qualquer método desde } \\
\text { que este seja apropriado e relevante. A norma não determi- } \\
\text { na uma periodicidade para a realização das avaliações. }\end{array}$ \\
\hline $\begin{array}{l}\text { Doações ou aquisição por } \\
\text { valores simbólicos }\end{array}$ & $\begin{array}{l}\text { Qualquer método pode ser adotado, desde que seja } \\
\text { apropriado e relevante. Testes de impairment podem ser } \\
\text { aplicados nos casos de deterioração física. }\end{array}$ \\
\hline Apresentação & $\begin{array}{l}\text { Devem ser evidenciados de forma segregada dos demais } \\
\text { ativos fixos. Quando os } H A s \text { não constam no BP, a enti- } \\
\text { dade deve explicar as razões para não fazê-lo, bem como } \\
\text { evidenciar a relevância e à natureza desses ativos nas NEs. }\end{array}$ \\
\hline Observação & $\begin{array}{l}\text { Tanto no BP quanto nas NEs, é preciso segregar os ativos } \\
\text { avaliados pelo custo ou por outro método. As variações de } \\
\text { avaliações e as doações devem ser incluídas nos resultados. } \\
\text { É preciso divulgar a data da avaliação, o método adotado, } \\
\text { o nome do avaliador e suas qualificações e limitações signi- } \\
\text { ficativas da avaliação. }\end{array}$ \\
\hline
\end{tabular}




\begin{tabular}{|c|c|}
\hline \multicolumn{2}{|c|}{$\begin{array}{l}\text { África do Sul } \\
\text { Standard of Generally Recognised Accounting Practice (GRAP) 103: heritage assets } \\
\text { (A ser implementado integralmente a partir de } 31 \text { de março de 2015) }\end{array}$} \\
\hline Capitalização & $\begin{array}{l}\text { Os HAs serão ativados se atenderem aos seguintes crité- } \\
\text { rios: houver benefícios econômicos futuros ou potencial } \\
\text { de serviço; e o custo ou o fair value puderem ser mensura- } \\
\text { dos com confiabilidade. }\end{array}$ \\
\hline Mensuração subsequente & $\begin{array}{l}\text { A reavaliação pode ter como base o custo ou o fair value. } \\
\text { Os } H A \text { s não podem ser depreciados, no entanto, pode ser } \\
\text { aplicado o teste de impairment. }\end{array}$ \\
\hline $\begin{array}{l}\text { Doações ou aquisição por } \\
\text { valores simbólicos }\end{array}$ & Nada consta. \\
\hline Apresentação & $\begin{array}{l}\text { Se os } H A s \text { não atenderem aos critérios de reconhecimento, } \\
\text { é requerido que tal fato seja evidenciado em NEs. }\end{array}$ \\
\hline Observação & $\begin{array}{l}\text { As despesas operacionais dos } H A s \text { serão reconhecidas no } \\
\text { superávit/déficit, quando incorridas. }\end{array}$ \\
\hline \multicolumn{2}{|l|}{$\begin{array}{l}\text { Brasil } \\
\text { NBC T } 16.10\end{array}$} \\
\hline Capitalização & Nada consta. \\
\hline Mensuração subsequente & Nada consta. \\
\hline $\begin{array}{l}\text { Doações ou aquisição por } \\
\text { valores simbólicos }\end{array}$ & Nada consta. \\
\hline Apresentação & Nada consta. \\
\hline Observação & $\begin{array}{l}\text { Não há norma específica relacionada aos } H A s \text {. A NBC T } \\
16.10 \text { trata de ativos e passivos da ADM Pública, no entan- } \\
\text { to, não há nenhuma referência aos } H A s \text {. }\end{array}$ \\
\hline \multicolumn{2}{|l|}{$\begin{array}{l}\text { Canadá } \\
\text { Section PS } 4240\end{array}$} \\
\hline Capitalização & $\begin{array}{l}\text { As coleções não são ativadas, pois não há como estimar os(1) } \\
\text { benefícios futuros de forma consistente. }\end{array}$ \\
\hline Mensuração subsequente & Nada consta. \\
\hline $\begin{array}{l}\text { Doações ou aquisição por } \\
\text { valores simbólicos }\end{array}$ & Nada consta. \\
\hline Apresentação & Nada consta. \\
\hline Observação & $\begin{array}{l}\text { Não há norma específica relacionada aos } H A s \text {. A eviden- } \\
\text { ciação das coleções é requerida; no entanto, regras para a } \\
\text { apresentação não constam na norma. }\end{array}$ \\
\hline \multicolumn{2}{|c|}{$\begin{array}{l}\text { Peru } \\
\text { (Manual Misterio de Economía y Finanzas) }\end{array}$} \\
\hline Capitalização & $\begin{array}{l}\text { Os } H A s \text { são contabilizados no ativo, sendo mensurados } \\
\text { pelo custo. }\end{array}$ \\
\hline $\begin{array}{l}\text { Mensuração subsequen- } \\
\text { te }\end{array}$ & Os HAs possuem vida ilimitada, logo, não são depreciáveis. \\
\hline $\begin{array}{l}\text { Doações ou aquisição } \\
\text { por valores simbólicos }\end{array}$ & $\begin{array}{l}\text { Não são mensurados e nem apresentados no Balanço (2) } \\
\text { Patrimonial. }\end{array}$ \\
\hline Apresentação & $\begin{array}{l}\text { Os HAs são evidenciados em rubrica específica denomina- } \\
\text { da Obras de Artes. }\end{array}$ \\
\hline
\end{tabular}




\begin{tabular}{|c|c|}
\hline Observação & Não há norma específica relacionada aos $H A s$. \\
\hline \multicolumn{2}{|c|}{$\begin{array}{l}\text { Argentina } \\
\text { RT } 17 \text { - Normas Contables Profesionales: Desarrollo de Cuestiones de aplicación general }\end{array}$} \\
\hline Capitalização & $\begin{array}{l}\text { Os } H A s \text { são contabilizados no ativo, sendo mensurados } \\
\text { pelo custo. }\end{array}$ \\
\hline Mensuração subsequente & Nada consta. \\
\hline $\begin{array}{l}\text { Doações ou aquisição por } \\
\text { valores simbólicos }\end{array}$ & Nada consta. \\
\hline Apresentação & $\begin{array}{l}\text { No Balanço Patrimonial, os HAs são apresentados dentro } \\
\text { da conta Bens de uso. }\end{array}$ \\
\hline Observação & Não há norma específica relacionada aos HAs. \\
\hline \multicolumn{2}{|c|}{$\begin{array}{l}\text { Estados Unidos } \\
\text { Statement of Federal Financial Accounting Standards } 29 \text { - heritage assets and Stewardship } \\
\text { Land }\end{array}$} \\
\hline Capitalização & $\begin{array}{l}\text { A regra é não efetuar a contabilização, com exceção dos } \\
\text { HAs multi-use. Quando contabilizados, se forem com- } \\
\text { prados ou construídos, devem ser registrados pelo custo } \\
\text { histórico. }\end{array}$ \\
\hline Mensuração subsequente & Nada consta. \\
\hline $\begin{array}{l}\text { Doações ou aquisição por } \\
\text { valores simbólicos }\end{array}$ & $\begin{array}{l}\text { HAs multi-use - devem ser reconhecidos preferencialmente } \\
\text { pelo valor escritural (book value); quando não for possível, } \\
\text { deve-se adotar ofair value. }\end{array}$ \\
\hline Apresentação & $\begin{array}{l}\text { HAs multi-use - deverá ser evidenciado na rubrica Imóveis, } \\
\text { instalações e equipamentos. }\end{array}$ \\
\hline Observação & $\begin{array}{l}\text { No caso dos HA que não são multi-use, os custos de } \\
\text { aquisição, de melhoria, de construção ou renovação serão } \\
\text { reconhecidos no resultado. }\end{array}$ \\
\hline \multicolumn{2}{|c|}{$\begin{array}{l}\text { International Accounting Standard (IAS) } \\
\text { International Public Sector Accounting Standard } 17 \text { - Property, Plant, and Equipment }\end{array}$} \\
\hline Capitalização & $\begin{array}{l}\text { A contabilização é facultativa. Quando ocorrem, os } H A s \\
\text { devem ser mensurados pelo custo. }\end{array}$ \\
\hline Mensuração subsequente & $\begin{array}{l}\text { Fair value com periodicidade regular, podendo ser reduzido por } \\
\text { valor recuperável e depreciações. Caso haja a reavaliação de um } \\
\text { ativo, toda a sua categoria do ativo deverá ser reavaliada. }\end{array}$ \\
\hline $\begin{array}{l}\text { Doações ou aquisição por } \\
\text { valores simbólicos }\end{array}$ & $\begin{array}{l}\text { O ativo deverá ser reavaliado a fair value na data da aquisi- } \\
\text { ção. }\end{array}$ \\
\hline Apresentação & Os ativos devem ser evidenciados por categoria. \\
\hline Observação & $\begin{array}{l}\text { São requeridas as seguintes informações: base de mensura- } \\
\text { ção, métodos de depreciação, valor contábil bruto. }\end{array}$ \\
\hline
\end{tabular}

Fonte: os autores.

Da análise do referido quadro, observa-se que os normativos citados se encontram em diversos estágios, visto que vão desde a ausência de normatização específica, como no caso do Brasil, Peru, Argentina e Canadá, até um arcabouço normativo robusto, como no caso da Nova Zelândia e da Austrália. Esse fato pode 
ser um indicador da relevância e importância que os $H A$ s apresentam para os diversos países, bem como a correspondente prestação de contas da gestão desses ativos à sociedade.

\section{PROCEDIMENTOS METODOLÓGICOS}

Esta seção tem por objetivo a caracterização do tipo de estudo realizado, do processo de investigação e das técnicas utilizadas na presente pesquisa. Ao atingir o objetivo proposto, será possível que outros pesquisadores interessados auditem os achados, atribuindo a ela maior validade de confiabilidade.

Para a classificação do presente estudo, segue-se o proposto por MatiasPereira (2012). Dessa forma, esta pesquisa classifica-se como aplicada, quanto à sua natureza; qualitativa, quando à forma de abordagem do problema; descritiva, quanto aos seus objetivos; e documental, quanto aos procedimentos técnicos. Quanto à construção da plataforma teórica da pesquisa, foi utilizada a pesquisa bibliográfica, a qual buscou autores internacionais que tratam das questões de reconhecimento e mensuração dos heritage assets.

A seleção da amostra dos relatórios anuais e das demonstrações contábeis dos museus foi realizada por conveniência; logo, é não probabilística, considerando a acessibilidade dos dados e, principalmente, a familiaridade dos autores com as Línguas Portuguesa, Inglesa e Espanhola.

Assim, a amostra foi composta inicialmente por 22 museus situados nos cinco continentes. Destes, restaram apenas nove em quatro continentes, os quais publicavam seus relatórios e suas demonstrações em uma das línguas citadas anteriormente. A seguir, é apresentado o Quadro 3, o qual tem o propósito de detalhar os museus pesquisados e os documentos analisados.

Quadro 3 - Amostra da pesquisa

\begin{tabular}{|l|l|l|l|}
\hline Continente & País & Museu & Documento analisado \\
\hline \multirow{3}{*}{ África } & África do Sul & $\begin{array}{l}\text { Iziko Museums of South } \\
\text { Africa (Iziko) }\end{array}$ & $\begin{array}{l}\text { Relatório Anual } \\
2013 / 2014\end{array}$ \\
\cline { 2 - 4 } & Egito & $\begin{array}{l}\text { Museum of Egyptian } \\
\text { Antiquities }\end{array}$ & Não disponível no site \\
\hline
\end{tabular}




\begin{tabular}{|c|c|c|c|}
\hline \multirow{6}{*}{ América } & Argentina & $\begin{array}{l}\text { Museo de Arte Latinoa- } \\
\text { mericano de Buenos Aires } \\
\text { (MALBA) }\end{array}$ & $\begin{array}{l}\text { Demonstrações contábeis } \\
\text { de } 2013 \text { da Fundação } \\
\text { Eduardo F. Costantini }\end{array}$ \\
\hline & Brasil & $\begin{array}{l}\text { Museu de Arte de São } \\
\text { Paulo Assis Chateau- } \\
\text { briand (MASP) }\end{array}$ & $\begin{array}{l}\text { Demonstrações contábeis } \\
\text { de } 2013\end{array}$ \\
\hline & Canadá & $\begin{array}{l}\text { The Montreal Museum } \\
\text { of Fine Arts }\end{array}$ & Relatório anual 2012/2013 \\
\hline & $\begin{array}{l}\text { Estados Uni- } \\
\text { dos }\end{array}$ & $\begin{array}{l}\text { The Metropolitan Mu- } \\
\text { seum of Art }\end{array}$ & Relatório anual 2012/2013 \\
\hline & México & Museo Soumaya & Não disponível no site \\
\hline & Peru & $\begin{array}{l}\text { Asociación Museo de Arte } \\
\text { de Lima }\end{array}$ & $\begin{array}{l}\text { Demonstrações Contá- } \\
\text { beis de } 2013\end{array}$ \\
\hline \multirow{5}{*}{ Ásia } & China & $\begin{array}{l}\text { National Museum of } \\
\text { China }\end{array}$ & Não disponível no site \\
\hline & Coreia do Sul & $\begin{array}{l}\text { National Musem of } \\
\text { Korea } \\
\text { The Natonal Folk } \\
\text { Musem of Korea }\end{array}$ & Não disponível no site. \\
\hline & Israel & Israel Museum & Não disponível no site \\
\hline & \multirow{2}{*}{ Japão } & \multirow{2}{*}{$\begin{array}{l}\text { National Museum of } \\
\text { Modern Art } \\
\text { National Museum of } \\
\text { Western Art }\end{array}$} & $\begin{array}{l}\text { Disponível apenas em } \\
\text { japonês. }\end{array}$ \\
\hline & & & Não disponível no site \\
\hline & Rússia & $\begin{array}{l}\text { The Pushkin State mu- } \\
\text { seum of Fine Arts } \\
\text { The State Hermitage }\end{array}$ & Não disponível no site \\
\hline \multirow[t]{3}{*}{ Europa } & França & Musée du Louvre & $\begin{array}{l}\text { Disponível apenas em } \\
\text { francês. }\end{array}$ \\
\hline & Inglaterra & The British Museum & Relatório anual 2014 \\
\hline & Itália & $\begin{array}{l}\text { Museu do Vaticano } \\
\text { Capitoline Museums }\end{array}$ & Não disponível no site \\
\hline \multirow[t]{2}{*}{ Oceania } & Austrália & $\begin{array}{l}\text { National Museum of } \\
\text { Australia }\end{array}$ & Relatório anual 2013/2014 \\
\hline & Nova Zelândia & $\begin{array}{l}\text { Museum of New Zealand } \\
\text { Te Papa Tongarewa }\end{array}$ & Relatório anual 2013/2014 \\
\hline
\end{tabular}

Fonte: os autores.

Conforme indica o Quadro 3, seis entidades publicaram o relatório anual, as quais apresentavam maior nível de detalhamento da gestão. No que diz respeito ao período, pode-se verificar que para quatro museus foi possível obter o relatório anual ou as demonstrações contábeis para os anos 2013/2014, enquanto para os demais se trabalhou com os documentos referentes a 2012/2013. 
Para a localização dos relatórios anuais/demonstrações contábeis, utilizouse a ferramenta de busca Google, fazendo-se uso de palavras-chave, relacionandoas aos museus que compõem a amostra. Na sequência, realizou-se a análise do conteúdo dos relatórios anuais/demonstrações contábeis com foco no tratamento contábil destinado aos heritage assets, verificando-se, principalmente, os critérios adotados para o reconhecimento e a mensuração desses ativos.

\section{ANÁLISE DAS DEMONSTRAÇÕES CONTÁBEIS DOS MUSEUS}

Com o intuito de organizar a apresentação descritiva dos diversos demonstrativos contábeis e suas respectivas Notas Explicativas (NEs), optou-se por categorizá-los em três níveis, tendo como critério de classificação o detalhamento dado aos HAs. No nível básico, foram classificadas as demonstrações dos Estados Unidos, Canadá, Brasil, Argentina e Peru. No intermediário, ficaram África do Sul e Reino Unido, enquanto no avançado foram classificadas as demonstrações da Nova Zelândia e da Austrália.

\section{1 NÍVEL BÁSICO NO TRATAMENTO DOS HERITAGE ASSETS}

Cabe relatar que as demonstrações contábeis de todos os integrantes desse grupo foram auditadas por auditores independentes; de forma geral, os pareceres indicaram que as demonstrações representavam de forma fidedigna o desempenho e a posição financeira das entidades, bem como estavam em conformidade com suas respectivas legislações.

Quanto ao reconhecimento dos $H A s$, observou-se que nos EUA (The Metropolitan Museum of Art) e no Canadá (The Montreal Museum of Fine Arts) esses ativos não são reconhecidos nas demonstrações financeiras e nem em suas Notas Explicativas. No que se refere a obras de arte recebidas em doação, o tratamento feito nos EUA é a exclusão dessas receitas na Declaração de Atividades, e as compras, os seguros e as vendas relacionadas a esses bens são registrados como diminuições e aumentos dos ativos líquidos na Declaração de Atividades. 
Já quanto ao tratamento das doações no Canadá, observou-se que a contabilização dos HAs é efetuada pelo valor justo, tendo como suporte laudos emitidos por avaliadores externos. No entanto, esses ativos são totalmente amortizados no ano de aquisição, possibilitando maior evidenciação e transparência dos ativos doados.

No Peru (Asociación Museo de Arte de Lima) e na Argentina (MALBA), observou-se que as coleções e as obras de arte são reconhecidas nas demonstrações financeiras. No Peru, o acervo de obras de artes é evidenciado no Balanço Patrimonial em rubrica própria, e na Argentina as obras de arte são aglutinadas na rubrica "bens de uso", ficando os HAs evidenciados apenas em Notas Explicativas. No que se refere à mensuração, observa-se que tanto o Peru quanto a Argentina mensuram seus HAs pelo custo, podendo, no caso do Peru, adotar o teste de impairment. No entanto, ambos não adotam depreciação, uma vez que entendem que os ativos possuem uma vida ilimitada.

No caso brasileiro, constatou-se que o MASP apresenta apenas uma parte do seu acervo no Balanço Patrimonial. Constam no balanço as obras existentes em 31 de dezembro de 1981, mensuradas pelo valor simbólico de $\mathrm{R} \$ 1,00$ para cada obra, e duas obras recebidas em 2010 e 2013, que foram registradas a fair value. Esse fato demonstra as limitações do tratamento contábil atribuído ao acervo de obras do MASP.

Quanto às doações de obras de arte recebidas, tanto no Peru quanto no Brasil, esses itens não foram reconhecidos nos balanços e nenhuma informação a respeito consta nas demonstrações contábeis do $M A L B A$.

\section{2 NÍVEL INTERMEDIÁRIO NO TRATAMENTO DOS HERITAGE ASSETS}

Atualmente, a instituição Iziko (África do Sul) não reconhece os HAs nas demonstrações contábeis e não evidencia esses ativos em suas Notas Explicativas. No entanto, a referida instituição encontra-se em um processo de transição no tratamento atribuído a esses ativos, tendo até 31 de março 2015 para se adaptar integralmente ao Standard of Generally Recognised Accounting Practice (GRAP) 103: heritage assets.

Quando os $H A$ s forem reconhecidos como ativos nos termos do GRAP 103, serão mensurados pelo custo; no entanto, se forem adquiridos sem nenhuma contrapartida, a sua mensuração será realizada pelo valor justo. As reavaliações deverão ser feitas com suficiente regularidade com o intuito de assegurar que o valor 
escriturado não difira materialmente do valor justo na data do balanço. Além disso, os HAs não deverão ser depreciados; no entanto, a entidade deverá avaliar, na data do balanço, se há necessidade de realizar o teste de impairment.

No Reino Unido (The British Museum), os HAs são classificados como bens do patrimônio não operacional e reconhecidos no grupo de Ativos Fixos e no subgrupo Heritage Assets, tanto para o Balanço Consolidado quanto para o Balanço Individual.

O Museu Britânico tem como marco temporal no que se refere ao tratamento dado aos bens culturais a data de 01 de abril de 2001. Os ativos culturais adquiridos ou recebidos em doação antes dessa data não são capitalizados nas demonstrações financeiras e nem evidenciados nas Notas Explicativas. Tal fato decorre de uma questão de praticidade, considerando que o custo de produzir a informação é superior aos benefícios gerados aos usuários das demonstrações financeiras, conforme consta nas notas explicativas.

Já quanto ao tratamento contábil para os $H A$ s adquiridos ou recebidos em doação após 01 de abril de 2001, verifica-se que estes foram capitalizados pelo custo (bens adquiridos) ou pelo valor de avaliação no momento da doação. Cabe relatar que as avaliações são realizadas durante o ano de aquisição por especialistas curatoriais internos com base em seu conhecimento especializado e, caso necessário, com referência às vendas de objetos semelhantes. A partir da análise das Notas Explicativas, observou-se que o custo ou valor não está sujeito à reavaliação, pois o custo de reavaliação não é compatível com os benefícios gerados aos usuários das demonstrações contábeis, considerando-se a relação custo-benefício da informação.

Para o Museu Britânico, os bens culturais são considerados como tendo vida útil indefinida, não se aplicando, portanto, depreciações. No entanto, esses ativos estão sujeitos a testes de impairment quando danos ou deteriorações são relatados. Observa-se que na própria Nota Explicativa são reconhecidas as limitações dos métodos de custo e valuation, considerando as características intrínsecas dos bens culturais. Quanto ao detalhamento dos $H A$ s, observou-se que nas Notas Explicativas esses ativos são classificados em grupos, bem como são demonstradas as variações dos últimos cinco anos, segregando-os em doados e adquiridos. 


\section{3 NÍVEL AVANÇADO NO TRATAMENTO DOS HERITAGE ASSETS}

A partir da análise do Relatório Anual 2013/2014 do Museum of New Zealand Te Papa Tongarewa, foi possível verificar que os heritage assets foram reconhecidos no Balanço Patrimonial pela entidade, sendo evidenciados no grupo Ativo Não Circulante, subgrupo Coleções. De acordo com as Notas Explicativas, inicialmente, tais ativos são reconhecidos pelo seu custo histórico, sendo modificados pelas reavaliações realizadas ao longo dos períodos.

Ainda que no Balanço Patrimonial os heritage assets estejam apresentados em uma única conta, as Notas Explicativas detalham a composição desses itens, indicado que são formados pelas seguintes coleções: Arqueológica, Arte, Botânica, Cerâmica, Biblioteca Te Aka Matua, História, Invertebrados, Maori, Coleção Filatélica, Pacífica e Internacional, Arquivos Fotográficos e Vertebrados. Também cabe destacar que para cada tipo de coleção são apresentados os aumentos/reduções em razão de aquisições, doações e reavaliações.

Além disso, nas Notas Explicativas constam as bases/metodologias de reavaliação, bem como os procedimentos adotados para cada classe de coleção.

No que diz respeito às bases/metodologias de reavaliação dos $H A s$, o museu adota critérios variados em razão do tipo de coleção. Em linhas gerais, esses ativos são avaliados pelo custo ou valor de mercado, com exceção das coleções definidas como Natural Environment, para as quais se toma como base o custo de reposição.

Em relação aos procedimentos empregados para a avaliação dos $H A s$, o museu tem como prática reavaliar suas coleções anualmente, com cada classe de coleção sendo reavaliada pelo menos uma vez a cada três anos. Os itens que formam as coleções Arqueológica, Arte, Cerâmica, Biblioteca Te Aka Matua, História, Maori, Filatélica, Pacífica e Internacional e Arquivo Fotográfico são avaliados por avaliadores independentes, enquanto a definições do valor das coleções Botânica, Vertebrados e Invertebrados foi realizada a partir de um modelo interno desenvolvido pelo Te Papa com base em custos/correntes de reposição.

Finalmente, cabe destacar que a administração considera que a depreciação não é aplicável aos heritage assets, uma vez que as coleções tendem a ter uma vida útil indefinida e geralmente não são de natureza depreciável. 
No caso do National Museum of Australia (Relatório Anual 2013/2014), os HAs estão evidenciados no Balanço Patrimonial no grupo Ativos Não Financeiros, subgrupo Imóveis, Instalações e Equipamentos.

Inicialmente, os HAs são reconhecidos pelo custo de aquisição, visto que após o reconhecimento inicial ao custo, passam a ser contabilizados pelo valor justo menos subsequentes depreciações e perdas por impairment acumuladas.

Nas Notas Explicativas, o museu apresenta, de forma detalhada, a mensuração a valor justo. A determinação do valor justo dos ativos classificados no grupo Heritage and cultural assets segue a abordagem de mercado, tendo como inputs os dados de mercados secundários locais e de todo o mundo para obras de arte e itens colecionáveis e a avaliação dos objetos. A mensuração do valor justo utilizada classifica-se no Nível 3 da hierarquia do valor justo, pois, considerando-se que não existem dados observáveis relevantes disponíveis, toma-se como base dados não observáveis para os ativos, sendo estes, principalmente, o valor das vendas privadas de obras de arte, antiguidades e similares colecionáveis e as avaliações profissionais de itens semelhantes.

No processo de avaliação, o museu utiliza a metodologia de amostragem, na qual os valores são determinados para a amostra de objetos selecionados de cada uma das categorias e, na sequência, um valor médio é aplicado à categoria de coleção inteira.

No que diz respeito à periodicidade, as avaliações independentes são realizadas a cada três anos por um avaliador que deve constar na lista de avaliadores aprovados pelo Cultural Gift Program administrado pelo Ministry for the Arts. No período transcorrido entre essas avaliações independentes, os movimentos de mercado são acompanhados e uma reavaliação gerencial ocorre quando há evidências de uma variação significativa de preços.

No período analisado nesta pesquisa, segundo indicam as Notas Explicativas, uma avaliação gerencial foi realizada.

Em relação à depreciação, o museu adota o método linear de depreciação, detalhando, nas Notas Explicativas, as taxas aplicáveis a cada categoria de ativo. No caso do grupo Heritage and Cultural assets, a vida útil utilizada como base para a depreciação fica entre 50 r 5.000 anos. A entidade declara que possui itens que são $H A s$ e ativos culturais os quais têm tempo de vida útil limitado e que, portanto, são depreciados.

Cabe destacar que nas demonstrações analisadas não constam valores de depreciação acumulada para essa categoria de ativos, bem como existe a informação de que não foram reconhecidas perdas por impairment. 


\section{4 ANÁLISE COMPARATIVA}

Com base na análise do conteúdo dos relatórios anuais, demonstrações contábeis e respectivas Notas Explicativas, apresentam, no Quadro 4, as principais práticas contábeis adotadas pelos museus no que diz respeito ao tratamento dos heritage assets.

Quadro 4 - Tratamento contábil dos heritage assets adotados pelos museus

\begin{tabular}{|l|l|}
\hline \multicolumn{2}{|l|}{ Nova Zelândia (Museum of New Zealand Te Papa Tongarewa) } \\
\hline Capitalização & $\begin{array}{l}\text { Os HAs são ativados e o reconhecimento inicial é feito } \\
\text { pelo custo de aquisição. }\end{array}$ \\
\hline Mensuração subsequente & $\begin{array}{l}\text { Inicialmente reconhecidos pelo custo histórico, sendo } \\
\text { modificados pelas reavaliações ao longo do tempo. }\end{array}$ \\
\hline Critérios de depreciação & Não há depreciação (vida útil ilimitada). \\
\hline $\begin{array}{l}\text { Doações ou aquisição por } \\
\text { valores simbólicos }\end{array}$ & Nada consta nos documentos analisados. \\
\hline Apresentação & $\begin{array}{l}\text { Evidenciados no Balanço Patrimonial - Ativo Não } \\
\text { Circulante, subgrupo Coleções. } \\
\text { As Notas Explicativas apresentam um detalhamento } \\
\text { robusto. }\end{array}$ \\
\hline Austrália (National Museum of Australia) \\
\hline Capitalização & $\begin{array}{l}\text { Os HAs são ativados e o reconhecimento inicial é feito } \\
\text { pelo custo de aquisição. }\end{array}$ \\
\hline Mensuração subsequente & $\begin{array}{l}\text { Valor justo, deduzidas as depreciações e perdas por } \\
\text { impairment. } \\
\text { A mensuração do valor justo utilizada classifica-se no } \\
\text { Nível 3 da hierarquia do valor justo. }\end{array}$ \\
\hline Critérios de depreciação & $\begin{array}{l}\text { Adota o método linear, o qual é detalhado nas Notas } \\
\text { Explicativas. }\end{array}$ \\
\hline $\begin{array}{l}\text { Doações ou aquisição por } \\
\text { valores simbólicos }\end{array}$ & Nada consta nos documentos analisados. \\
\hline \multirow{2}{*}{ Apresentação } & $\begin{array}{l}\text { Apresentados no Balanço Patrimonial - Ativos Não } \\
\text { Financeiros, subgrupo Imóveis, Instalações e Equipa- } \\
\text { mentos. } \\
\text { As Notas Explicativas apresentam um detalhamento } \\
\text { robusto. }\end{array}$ \\
\hline Reino Unido (The British Museum) \\
\hline $\begin{array}{l}\text { HAs adquiridos a partir 01 de abril de 2001 são reconhe- } \\
\text { cidos pelo custo ou valor de avaliação no momento da } \\
\text { aquisição. } \\
\text { HAs adquiridos antes de 01 de abril de 2001 não estão } \\
\text { capitalizados, pois o custo de avaliação é superior ao } \\
\text { benefício gerado pela informação. }\end{array}$ \\
\hline
\end{tabular}




\begin{tabular}{|c|c|}
\hline Mensuração subsequente & $\begin{array}{l}\text { O } H A \text { não está sujeito à reavaliação, pois o custo de } \\
\text { reavaliação não é compatível com os benefícios gerados } \\
\text { aos usuários da informação. } \\
\text { Perdas por impairment podem ser registradas quando } \\
\text { danos ou deterioração são relatados. }\end{array}$ \\
\hline Critérios de depreciação & Não há depreciação (vida útil ilimitada). \\
\hline $\begin{array}{l}\text { Doações ou aquisição por } \\
\text { valores simbólicos }\end{array}$ & $\begin{array}{l}\text { Apenas os } H A s \text { recebidos em doação a partir01 de abril } \\
\text { de } 2001 \text { são ativados, sendo avaliados no ano de aquisi- } \\
\text { ção por especialistas curatoriais internos. }\end{array}$ \\
\hline Apresentação & $\begin{array}{l}\text { Evidenciados no Balanço Patrimonial - Ativos Fixos, } \\
\text { subgrupo heritage assets. }\end{array}$ \\
\hline \multicolumn{2}{|c|}{ África do Sul (Iziko Museums of South Africa (Iziko)) } \\
\hline Capitalização & $\begin{array}{l}\text { Os HAs não são reconhecidos nas demonstrações contá- } \\
\text { beis e não constam nas Notas Explicativas. }\end{array}$ \\
\hline Mensuração subsequente & Nada consta nos documentos analisados. \\
\hline Critérios de depreciação & Nada consta nos documentos analisados. \\
\hline $\begin{array}{l}\text { Doações ou aquisição por } \\
\text { valores simbólicos }\end{array}$ & Nada consta nos documentos analisados. \\
\hline Apresentação & Nada consta nos documentos analisados. \\
\hline \multicolumn{2}{|c|}{ Brasil (Museu de Arte de São Paulo Assis Chateaubriand (MASP)) } \\
\hline Capitalização & $\begin{array}{l}\text { Atualmente, as obras de arte não são reconhecidas pelo } \\
\text { Museu. }\end{array}$ \\
\hline Mensuração subsequente & $\begin{array}{l}\text { As obras do acervo existentes em } 31 \text { de dezembro de } \\
1981 \text { estão apresentadas pelo valor simbólico de R } \$ 1,00 \\
\text { cada, exceto duas obras recebidas em doação, que foram } \\
\text { registradas a valor justo. }\end{array}$ \\
\hline Critérios de depreciação & Nada consta nos documentos analisados. \\
\hline $\begin{array}{l}\text { Doações ou aquisição por } \\
\text { valores simbólicos }\end{array}$ & $\begin{array}{l}\text { Com exceção de duas obras de arte, desde } 31 \text { de dezem- } \\
\text { bro de 1981, as doações recebidas não estão refletidas } \\
\text { nos registros contábeis. }\end{array}$ \\
\hline Apresentação & $\begin{array}{l}\text { As obras de arte contabilizadas estão evidenciadas no } \\
\text { item Acervos de Obra de Arte no Ativo não Circulante. } \\
\text { As Notas Explicativas apresentam a quantidade de peças } \\
\text { de cada coleção, sem mensuração do valor. }\end{array}$ \\
\hline \multicolumn{2}{|c|}{ Canadá (The Montreal Museum of Fine Arts) } \\
\hline Capitalização & $\begin{array}{l}\text { Os HAs adquiridos não são reconhecidos nas demons- } \\
\text { trações contábeis e não constam nas Notas Explicativas. }\end{array}$ \\
\hline Mensuração subsequente & Nada consta nos documentos analisados. \\
\hline Critérios de depreciação & Nada consta nos documentos analisados. \\
\hline $\begin{array}{l}\text { Doações ou Aquisição por } \\
\text { valores simbólicos }\end{array}$ & $\begin{array}{l}\text { Os } H A s \text { são ativados a valor justo com base em laudos } \\
\text { de avaliação externos, mas são totalmente amortizados } \\
\text { no mesmo ano de aquisição. }\end{array}$ \\
\hline Apresentação & Nada consta nos documentos analisados. \\
\hline \multicolumn{2}{|c|}{ Peru (Asociación Museo de Arte de Lima) } \\
\hline Capitalização & $\begin{array}{l}\text { Os } H A s \text { são ativados e o reconhecimento inicial é feito } \\
\text { pelo custo de aquisição. }\end{array}$ \\
\hline
\end{tabular}




\begin{tabular}{|l|l|}
\hline Mensuração subsequente & O museu realiza teste de impairment para as coleções. \\
\hline Critérios de depreciação & Não há depreciação registrada. \\
\hline $\begin{array}{l}\text { Doações ou aquisição por } \\
\text { valores simbólicos }\end{array}$ & $\begin{array}{l}\text { Os } H A s \text { recebidos em doação não são mensurados, nem } \\
\text { são apresentados no BP. }\end{array}$ \\
\hline Apresentação & $\begin{array}{l}\text { Obras adquiridas são evidenciadas no Balanço Patrimo- } \\
\text { nial, na rubrica Obras de Arte. }\end{array}$ \\
\hline Argentina (Museo de Arte Latinoamericano de Buenos Aires (MALBA)) \\
\hline Capitalização & Os HAs são ativados e mensurados ao custo. \\
\hline Mensuração subsequente & Nada consta nos documentos analisados. \\
\hline Critérios de depreciação & Não há depreciação registrada. \\
\hline $\begin{array}{l}\text { Doações ou aquisição por } \\
\text { valores simbólicos }\end{array}$ & Nada consta nos documentos analisados. \\
\hline Apresentação & $\begin{array}{l}\text { Evidenciadas no Balanço Patrimonial, no grupo Bens } \\
\text { de uso. }\end{array}$ \\
\hline EUA (The Metropolitan $\boldsymbol{M u s e u m}$ of Art) \\
\hline $\begin{array}{l}\text { Capitalização } \\
\text { Apresentação }\end{array}$ & $\begin{array}{l}\text { Os HAs não são reconhecidos nas demonstrações contá- } \\
\text { beis e não constam nas Notas Explicativas. } \\
\text { As compras de objetos de arte pelo Museu são registadas } \\
\text { como uma diminuição nos ativos líquidos na Declara- } \\
\text { ção de Atividades. }\end{array}$ \\
\hline Nada consta nos documentos analisados. \\
\hline valores simbólicos & Nada consta nos documentos analisados. \\
\hline Critérios de depreciação & $\begin{array}{l}\text { O Museu declara que, em conformidade com as práti- } \\
\text { cas contábeis geralmente seguidas pelos museus de arte, } \\
\text { o valor das coleções do Museu foi excluído do Balanço } \\
\text { Patrimonial. }\end{array}$ \\
\hline
\end{tabular}

Fonte: os autores.

A partir da análise do Quadro 4, observa-se que as práticas adotadas pelo Museum of New Zealand Te Papa Tongarewa (Nova Zelândia) e pelo National Museum of Australia (Austrália), no que diz respeito ao reconhecimento, à mensuração subsequente e à apresentação dos heritage assets, estão em linha com o que determinam as normas contábeis dos países em questão. Em relação ao tratamento das doações, em ambas as normas a orientação é de que os bens doados sejam avaliados pelo valor justo, visto que não foi possível identificar, a partir dos documentos analisados, os procedimentos adotados pelos museus, uma vez que estes não foram detalhados.

No caso do Reino Unido (The British Museum), constata-se que o tratamento atribuído aos $H A$ s também está em consonância com o que prevê a norma contábil aplicável. Destaca-se aqui que o Financial Reporting Standard 30: Heritage assets, emitido pelo Accounting Standards Board (ASB) prevê que o custo de geração das informações 
não deve ser superior ao benefício gerado pela sua disponibilização, sendo essa questão considerada pelo Museu no processo de elaboração das demonstrações contábeis. Quanto ao tratamento dos bens doados, a norma define que qualquer método de avaliação pode ser utilizado, desde que seja apropriado e relevante, logo, entende-se que também nesse caso o Museu observou o que estabelece o FRS 30.

No que diz respeito ao tratamento contábil aplicado aos HAs pelo Iziko Museums of South Africa, é importante destacar o período de transição pelo qual os museus da África do Sul estão passando. No momento atual, os ativos dessa natureza não são reconhecidos nas demonstrações contábeis ou evidenciados em Notas Explicativas, contudo, a partir da adoção integral do Accounting Standard on Heritage Assets: GRAP 103, que deve ocorrer até 31 de março de 2015, espera-se um aumento na qualidade das informações disponibilizadas, uma vez que o reconhecimento dos $H A s$ e/ou evidenciação em Notas Explicativas pelas entidades está previsto no normativo.

No Brasil, não há norma específica para o tratamento contábil dos heritage assets; o Museu de Arte de São Paulo Assis Chateaubriand (MASP) contabilizou apenas parte do acervo (existentes em 31 de dezembro de 1981), considerando um valor simbólico de $\mathrm{R} \$ 1,00$ por obra de arte, e registrou duas obras a valor justo. Segundo consta na Nota Explicativa n. 10: "Em sua totalidade, as obras foram recebidas por doações, não tendo sido refletido contabilmente o correspondente acréscimo patrimonial a cada doação.”

O Museu situado no Canadá (The Montreal Museum of Fine Arts) observa o que está previsto nas normas aplicáveis ao país para o reconhecimento e a mensuração subsequente dos bens adquiridos, observando-se que os valores das coleções adquiridas não constam nas demonstrações contábeis. Em relação às doações, o Museu declara reconhecer os itens doados a valor justo, amortizando-as no ano de aquisição. Esse procedimento não está previsto nas normas, e a entidade não justifica a sua realização. Já no que diz respeito à evidenciação dos $H A s$, a norma requer a divulgação desses ativos, mas não cria regras para a sua apresentação nas Notas Explicativas.

A Asociación Museo de Arte de Lima (Peru) também adota procedimentos que, em linhas gerais, estão de acordo com o que determinam as normas aplicáveis no país, visto que, nesse caso, é importante destacar que inexiste uma regulamentação específica sobre a contabilização dos heritage assets, e as entidades seguem o exposto pelo manual emitido pelo Ministério da Fazenda. Apenas no caso da mensuração subsequente, verificou-se que o Museu se refere à realização de teste de impairment, o que não consta na norma. 
$\mathrm{Na}$ Argentina, também não há norma que trata da contabilização dos $H A s$, e o Museo de Arte Latinoamericano de Buenos Aires (MALBA) observa o exposto nas Resoluções Técnicas (RTs) da Federação Argentina dos Conselhos Profissionais de Ciências Econômicas. O Museu segue o definido na RT em relação ao reconhecimento inicial e à evidenciação dos $H A s$, mas na demonstração consultada, nada consta sobre a sua mensuração subsequente e contabilização dos bens recebidos em doação. Da mesma forma, orientações sobre essas questões não fazem parte da RT.

Finalmente, no caso do Metropolitan Museum of Art (EUA), verifica-se que a norma aplicável é seguida, visto que os $H A s$ não são contabilizados. Destaca-se a informação relatada pelo Museu de que os para bens recebidos em doação é efetuada a exclusão das receitas na Declaração de Atividade, porém, tal orientação não consta na norma.

Em relação ao tratamento contábil dos heritage assets discutido na literatura, é possível observar, a partir da análise do Quadro 4, que dos nove museus analisados, cinco (Nova Zelândia, Austrália, Reino Unido, Peru e Argentina) evidenciam esses bens no Balanço Patrimonial, o que indica que assim como observado na revisão da literatura, não existe unanimidade quanto ao reconhecimento desses itens no ativo.

Quanto aos critérios de mensuração propostos pela literatura, observa-se uma escassez de trabalhos científicos que abordam empiricamente os métodos sintetizados no Quadro 1, principalmente no contexto contábil e direcionados à análise de critérios adequados a serem utilizados com o objetivo de melhorar a qualidade informacional dos relatórios. Entre os métodos identificados na revisão da literatura, constatou-se que o método analisado com maior frequência é o custo de viagem, sendo este geralmente utilizado na mensuração de $H A s$ ligados ao turismo, considerando as premissas a serem adotadas. Apesar disso, não se observou, a partir da análise das demonstrações contábeis dos museus, a utilização desse critério de mensuração.

$\mathrm{Na}$ verdade, no que diz respeito aos critérios de mensuração adotados pelos museus que contabilizam seus $H A s$, observou-se que apenas o custo histórico (Nova Zelândia, Austrália, Reino Unido, Peru e Argentina), o valor justo (Austrália), o valor de mercado (Nova Zelândia), o custo de reposição (Nova Zelândia) e o julgamento de profissionais especializados (Reino Unido) são adotados. Em linhas gerais, predomina a utilização do custo histórico para o reconhecimento inicial, sendo os demais critérios mencionados adotados na mensuração subsequente. 


\section{CONSIDERAÇÕES FINAIS}

Conforme se pode depreender do presente estudo, o reconhecimento e a mensuração dos heritage assets continuam sendo um desafio aos estudiosos, pesquisadores e profissionais da Contabilidade, considerando as características intrínsecas desses ativos, como a questão da vida útil e o seu valor social para as nações.

Com o objetivo de efetuar a análise de como o reconhecimento e a mensuração dos HAs estão sendo tratados nas demonstrações contábeis dos diversos museus pesquisados, optou-se por abordar esses critérios sob a perspectiva dos principais autores, dos órgãos reguladores e das práticas adotadas pelos museus, as quais foram sumarizadas e detalhadas nos Quadros 1, 2 e 4.

No que se refere ao reconhecimento, observam-se entidades que não reconhecem os ativos em questão nas demonstrações contábeis, sendo esse o caso dos museus localizados nos Estados Unidos, Canadá e Brasil. No entanto, os museus situados na Nova Zelândia, Austrália, Peru e Argentina capitalizam os HAs. Cabe ressaltar que no conjunto dos países que capitalizam os $H A s$ há uma diferenciação substancial quanto ao nível de evidenciação nas demonstrações e Notas Explicativas, sendo a Nova Zelândia e a Austrália os países que apresentam o detalhamento mais completo e robusto.

Quanto aos critérios de mensuração adotados pelos museus, verifica-se que o custo histórico é adotado principalmente para o reconhecimento inicial, enquanto outros critérios (valor justo, valor de mercado, custo de reposição e julgamento de profissionais especializados) são utilizados na mensuração subsequente. Ressalta-se que os demais critérios de mensuração abordados na literatura pesquisada não são usados pelos museus.

Tanto o Reino Unido quanto a África do Sul apresentam peculiaridades quanto à ativação e mensuração dos ativos culturais. No caso do Reino Unido, se o custo de ativação for maior que o benefício da informação produzida pelos $H A s$, não há a necessidade de ativar, existindo apenas a obrigação de evidenciar tal fato nas Notas Explicativas; já quanto à mensuração, qualquer método pode ser utilizado, desde que seja apropriado e relevante. Quanto à África do Sul, cabe relatar que esse país está passando por um período de transição e que o reconhecimento e a mensuração serão requeridos a partir de 31 de março de 2015.

Dessa forma, pode-se concluir que tanto a prática adotada pelos museus quanto a normatização dos órgãos reguladores são diversificadas no que se refere ao reconhecimento e às bases de mensuração dos heritage assets. De fato, não há consenso 
sobre qual é o tratamento mais adequado para esse tipo de ativo, e a literatura expõe fragilidades das práticas adotadas que podem limitar a capacidade informacional das demonstrações contábeis, o que indica que ainda há espaço para que a Contabilidade desenvolva os modelos teóricos atualmente existentes com o intuito de aprimorar o tratamento contábil dos HAs.

Como principal limitação desta pesquisa, pode-se mencionar o tamanho da amostra, uma vez que o foco foram os museus que publicavam as suas demonstrações contábeis apenas nas Língua Inglesa, Portuguesa ou Espanhola. Em pesquisas futuras, recomenda-se ampliar o tamanho da amostra, contemplando entidades cujas demonstrações tenham sido elaboradas em outros idiomas, ampliando-se as bases de comparação.

\section{REFERÊNCIAS}

ACCOUNTING STANDARD BOARD. Financial reporting standard 30: heritage assets. London: ASB, 2009. Disponível em: < http://frc.org.uk/Our-Work/ Publications/ASB/FRS-30-Heritage-Assets-(June-2009)-File.pdf > . Acesso em: 28 jun. 2014.

\section{ACCOUNTING STANDARDS BOARD. Standard of Generally} Recognised Accounting Practice GRAP 103: heritage assets. South Africa: ASB, 2008. Disponível em: < http://www.asb.co.za/LinkClick. aspx?fileticket=kK9yP5JCcNw\%3d\&portalid=0 > . Acesso em: 28 jan. 2015.

\section{AUSTRALIAN ACCOUNTING STANDARDS BOARD. Australian}

Accounting Standards Board AASB 116: property, plant and equipment. Australia: AASB, 2014. Disponível em: < http://www.aasb.gov.au/admin/file/ content105/c9/AASB116_07-04_COMPjun14_07-14.pdf>. Acesso em: 28 jan. 2015.

BARTON, A. D. Accounting for public heritage facilities: assets or liabilities of the government? Accounting, Auditing \& Accountability Journal, v. 13, n. 2, p. 219-235, 2000.

BARTON, A. D. The conceptual arguments concerning accounting for public heritage assets: a note. Accounting, Auditing \& Accountability Journal, v. 18, n. 3, p. 434-440, 2005.

BEDATE, A.; HERRERO, L. C.; SANZ, J. A. Economic valuation of the cultural heritage: application to four case studies in Spain. Journal of Cultural Heritage, v. 5, n. 1, p.101-111, 2004. 
BIONDI, L.; LAPSLEY, I. Accounting, transparency and governance: the heritage assets problem. Qualitative Research in Accounting \& Management, v. 11, n. 2, p. 146-164, 2004.

CARNEGIE, G. D.; WOLNIZER, P. W. The financial value of cultural, heritage and scientific collections: an accounting fiction. Australian Accounting Review, v. 5, n. 1, 1995.

CONSELHO FEDERAL DE CONTABILIDADE. Resolução CFC n. 1.137/08, de 21 de novembro de 2008. Aprova a NBC T 16.10 - Avaliação e Mensuração de Ativos e Passivos em Entidades do Setor Público. Brasília, DF, 2008. Disponível em: <http://www.cfc.org.br/sisweb/sre/detalhes_sre.aspx?Codigo=2008/001137> . Acesso em: 28 jan. 2015.

ELLWOOD, S.; GREENWOOD, M. Accounting for Heritage Assets: Does measuring economic value kill the cat? In: EUROPEAN ACCOUNTING ASSOCIATION, 37., 2014, Estonia. Anais eletrônicos... Estonia: European Accounting Association, 2014. Disponível em: < http://www.eaa2014.org/userfiles/ file/08\%20EAA\%20-\%20PS.pdf>. Acesso em: 28 jun. 2014.

FEDERACIÓN ARGENTINA DE CONSEJOS PROFESIONALES DE CIENCIAS ECONÓMICAS. Resolución Técnica n. 17. Normas Contables Profesionales Desarrollo de Cuestiones de Aplicación General. Disponível em: $<$ http://www.consejo.org.ar/institucional/normas_profesionales.html > . Acesso em: 28 jan. 2015.

FINANCIAL ACCOUNTING STANDARDS ADVISORY BOARD.

Statement of Federal Financial Accounting Standards 29: heritage assets and stewardship land. Washington: Fasab, 2008. Disponível em: < http://www.fasab. gov/pdffiles/sffas_29.pdf>. Acesso em: 28 jun. 2014.

HOOPER, K.; KEARINS, K.; GREEN, R. Knowing "the price of everything and the value of nothing": accounting for heritage assets. Accounting, Auditing $\&$ Accountability Journal, v. 18, n. 3, p. 410-433, 2005.

INSTITUTE OF CHARTERED ACCOUNTANTS OF NEW ZEALAND. Financial Reporting Standard n. 3: accounting for property, plant and equipment. New Zealand: NZICA, 2001. Disponível em: < https://frc.org.uk/ getattachment/02239b10-1540-4100-879e-e4a5c15e887c/FRS-3-ReportingFinancial-Performance.aspx> . Acesso em: 28 jan. 2015. 
INTERNATIONAL FEDERATION OF ACCOUNTANTS. International Public Sector Accounting Standard 17: property, plant and equipment. New York: IPSASB, 2006. Disponível em: < https://www.ifac.org/sites/default/files/ publications/files/ipsas-17-property-plant.pdf > . Acesso em: 28 jun. 2014.

LOPES, F. J.; FREIRE. F. de S. Métrica de valoração ambiental: uma percepção da gestão pública no município de Cavalcante. In: EnANPAD, 38., 2014, Rio de Janeiro. Anais... Rio de Janeiro, 2014. Disponível em:<http://www.anpad.org.br/ admin/pdf/2014_EnANPAD_CON 1546 . pdf > . Acesso em 24 abr. 2015.

MARQUES, M. de M. Mensuração de ativos culturais: uma aplicação do método do custo de viagem em bens públicos culturais do Distrito Federal. 2012. 127 p. Dissertação (Mestrado em Ciências Contábeis)Universidade Brasília, Universidade Federal da Paraíba e Universidade Federal do Rio Grande do Norte, Brasília, 2012.

MATIAS-PEREIRA, J. Manual de metodologia de pesquisa científica. São Paulo: Atlas, 2012.

MAUTZ, R. K. Financial reporting: should government emulate business? Joumal of Accountancy, 1981.

MAUTZ, R. K. Monuments, Mistakes, and Opportunities. Accounting Horizons, 1988.

MICALLEF, F.; PEIRSON G. Financial reporting of cultural, heritage, scientific and community collections. Australian Accounting Review, v. 7, n. 1, 1997.

PALLOT, June. The nature of public asset: a response to Mautz. Accounting Horizons, 1990.

PIRES, Charline B.; NIYAMA, Jorge K. Heritage Assets: desafios para a sua mensuração. In: I CONGRESSO UNISINOS DE CONTROLADORIA E FINANÇAS 2014, São Leopoldo, 2014. Anais eletrônicos... São Leopoldo: Unisinos, 2014. Disponível em: < http://www. unisinos.br/eventos/cofin/images/ conteudo/docs/anais-tc-2014.pdf>. Acesso em: 25 jan. 2015.

PLAN CONTABLE GENERAL PARA EMPRESAS. Disponível em: < https:// www.mef.gob.pe/contenidos/conta_publ/documentac/PCGE_Final111008.pdf $>$. Acesso em: 25 jan. 2015.

PLAZA, B. Valuing museums as economic engines: Willingness to pay or discounting of cash-flows? Journal of Cultural Heritage, v. 11, n. 2, p. 155-162, 2010. 
PUBLIC SECTOR ACCOUNTING BOARD. Summary comparison of the PS 4200 series and other standards in the CICA Public Sector Accounting Handbook. Disponível em: <http://www.frascanada.ca/standards-for-publicsector-entities/resources/reference-materials/item49205.pdf > . Acesso em: 28 jan. 2015.

WILD, Susan. Accounting for Heritage, Cultural and Community Assets - Alternative Metrics from a New Zealand Maori Educational Institution. Australasian Accounting Business \& Finance Journal, v. 7, n. 1, 2013.

\section{Como citar este artigo:}

PIRES, C. B. et al. Heritage assets: procedimentos para o reconhecimento e 艺 mensuração adotados pelos museus. RACE, Revista de Administração, Contabilidade e Economia, v. 14, n, 2, p. 623-652, maio/ago. 2015. Disponível $\varangle_{\text {em: }}<$ http://editora.unoesc.edu.br/index.php/race>. Acesso em: dia/mês/ ano.

Pires, C. B., Ribeiro, D. C., Niyama, J. K., \& Matias-Pereira, J. (2015) Heritage

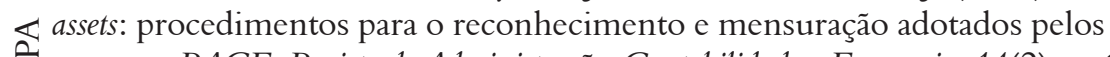
museus. RACE, Revista de Administração, Contabilidade e Economia, 14(2), p. 623-652. Recuperado em dia/mês/ ano de http://editora.unoesc.edu.br/index.php/race 